\title{
ANGIODYSPLASIA AS THE CAUSE OF MASSIVE LOWER GASTROINTESTINAL HAEMORRHAGE IN A YOUNG ADULT
}

\author{
Probhas Kumar Sarkar1, Saurabh Das², Bappaditya Sarkar³, Kumar Dheeraj, Partha Sarathi Mandal5 \\ 1Professor, Department of General Surgery, I. P. G. M. E and R. and S. S. K. M. Hospital, Kolkata. \\ ${ }^{2}$ Assistant Professor, Department of General Surgery, I. P. G. M. E and R. and S. S. K. M. Hospital, Kolkata. \\ ${ }_{3}^{3}$ RMO cum Clinical Tutor, Department of General Surgery, I. P. G. M. E and R. and S. S. K. M. Hospital, Kolkata. \\ ${ }_{4}^{4}$ Postgraduate Trainee, Department of General Surgery, I. P. G. M. E and R. and S. S. K. M. Hospital, Kolkata. \\ ${ }_{5}^{5}$ Postgraduate Trainee, Department of General Surgery, I. P. G. M. E and R. and S. S. K. M. Hospital, Kolkata.
}

\section{ABSTRACT}

\section{BACKGROUND}

Vascular ectasia of colon, synonymous with angiodysplasia, arteriovenous malformation and angioectasia are the frequent cause of recurrent lower intestinal bleeding after age 60 years, ${ }^{1}$ but rarely found in young adults. ${ }^{2}$ So diagnosis of angiodysplasia in younger age group is even more difficult. We present a case of massive bleeding from terminal ileal and colonic angiodysplasia, a 20-year-old male to increase awareness of this uncommon but potentially life-threatening cause of lower intestinal bleeding in younger age group.

\section{MATERIALS AND METHODS}

A 20-year-old male patient admitted with fresh bleeding per rectum (2-3 times/day) since 15 days. Abdominal CT angiogram showed vascular malformation at right colon and terminal ileum, likely angiodysplasia. Right hemicolectomy with terminal $80 \mathrm{cms}$ of ileal resection and ileotransverse anastomosis done.

\section{RESULTS}

Histological review of the specimen showed - Vascular malformation likely angiodysplasia. Postoperatively, patient recovered uneventfully with no further episodes of bleeding per rectum. A review of literature was undertaken to make clear the significance of vascular malformations as the cause of massive lower gastrointestinal haemorrhage in young adult.

\section{CONCLUSION}

This is one of the few reports that documents histologically a vascular malformations, likely angiodysplasia as the source of massive lower gastrointestinal haemorrhage in a young adult.

\section{KEYWORDS}

Angiodysplasia, Vascular Malformation.

HOW TO CITE THIS ARTICLE: Sarkar PK, Das S, Sarkar B, et al. Angiodysplasia as the cause of massive lower gastrointestinal haemorrhage in a young adult. J. Evolution Med. Dent. Sci. 2016;5(86):6432-6434, DOI: 10.14260/jemds/2016/1455

\section{CASE REPORT}

A 20 years old male patient referred from gastromedicine for surgical consultation for complaints of -

- $\quad$ Fresh bleeding per rectum (2-3 times/day) since 15 days.

- Bleeding was associated with postural symptoms giddiness and blackouts and patient received 18 units of blood transfusion over the duration.

\section{Past History}

- 20 days and patient required multiple blood transfusions.

- At that time UGIE, Meckel's scan, sigmoidoscopy, colonoscopy (Upto Lt transverse colon)-Normal.

Financial or Other, Competing Interest: None.

Submission 09-09-2016, Peer Review 13-10-2016,

Acceptance 20-10-2016, Published 27-10-2016.

Corresponding Author:

Dr. Probhas Kumar Sarkar,

70/12,

Bamacharan Roy Road,

Kolkata-700034.

E-mail: sarkarprobhas@gmail.com

DOI: $10.14260 /$ jemds/2016/1455

\section{General Survey}

Afebrile, severe pallor.

B.P. - 90/50, pulse - 112/min low volume.

$\mathrm{P} / \mathrm{A}$ - Soft, elastic and flat. No organomegaly.

Investigation - $\mathrm{Hb} \%$ - 4.6, PCV - 14.8, platelet - 1.5 lakh/cumm,

TLC - 5600/cumm.

LFT - bilirubin - 0.6

$\mathrm{P}$ - Time - $13 \mathrm{sec}$, INR - 1.1

RFT - Na+/K+ :- $128 / 4.2$

Urea/creatinine $-52 / 0.9$

UGIE - Normal

Colonoscopy (Seen upto mid-transverse colon) - Rectum, sigmoid, descending and transverse colon covered with liquid black stool and blood clots.

Visualised mucosa - Normal.

TAS - Mild ascites with internal echoes.

Abdominal CT angiogram - Vascular malformation with multiple tortuous vessels and some interspersed aneurysms seen involving caecum, proximal ascending colon and terminal ileum. Arterial supply is from branches of SMA via right colic branches and ileocolic artery. 


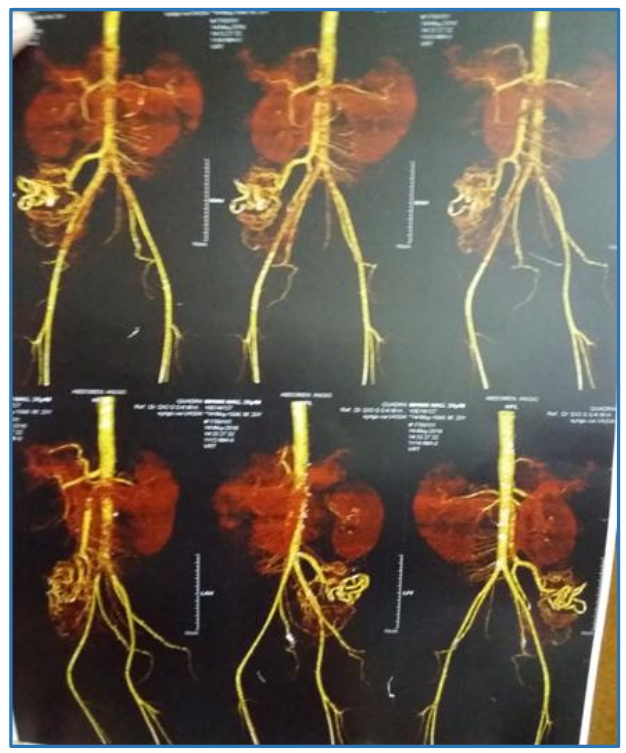

With radiological diagnosis of angiodysplasia at right colon and terminal ileum and severe previous episodes of fresh bleeding per rectum associated with haemodynamic instability.

Plan of surgical exploration was made. Per-operative finding - at laparotomy - multiple dilated, tortuous and pulsatile vessels noted on anti-mesenteric side of terminal ileum centered around $20 \mathrm{cms}$. proximal to i-c junction with bluish - purple intraluminal content visible through serosal surface seen up to $60 \mathrm{cms}$. proximal to i-c junction s/o altered intraluminal blood. No other eternal pathology found.

\section{Procedure}

Right hemicolectomy with terminal $80 \mathrm{cms}$. of ileal resection and ileotransverse anastomosis performed.

The patient got well in the post-operative period with no further bleeding episodes and discharged from hospital on $10^{\text {th }}$ postop day.

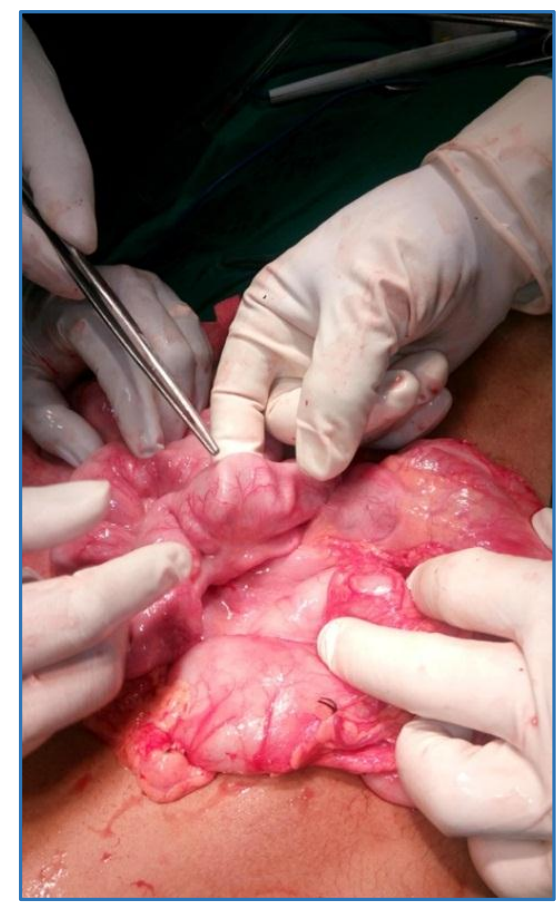

Dilated submucosal vessels in terminal ileum

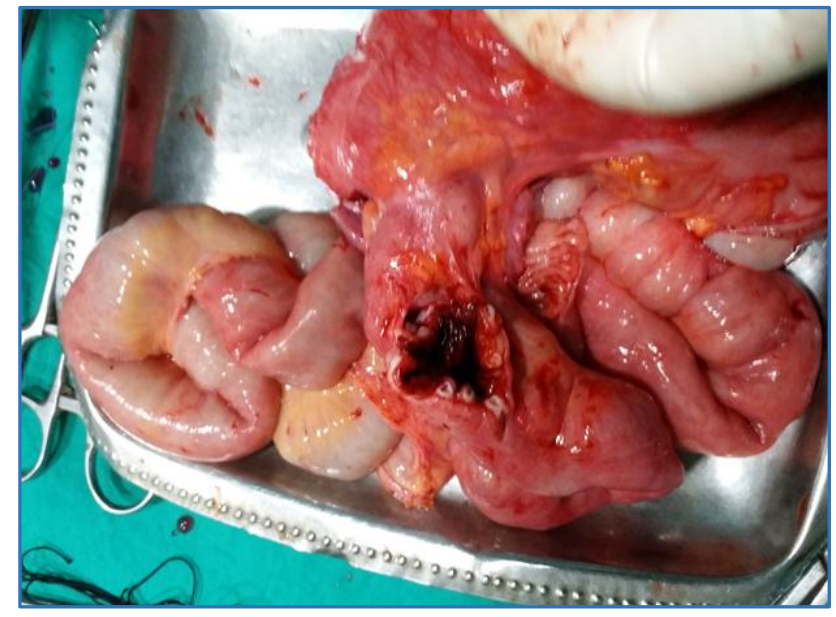

Cut open section of the specimen showing dilated intramural vessels and altered blood in lumen in region of Ascending colon

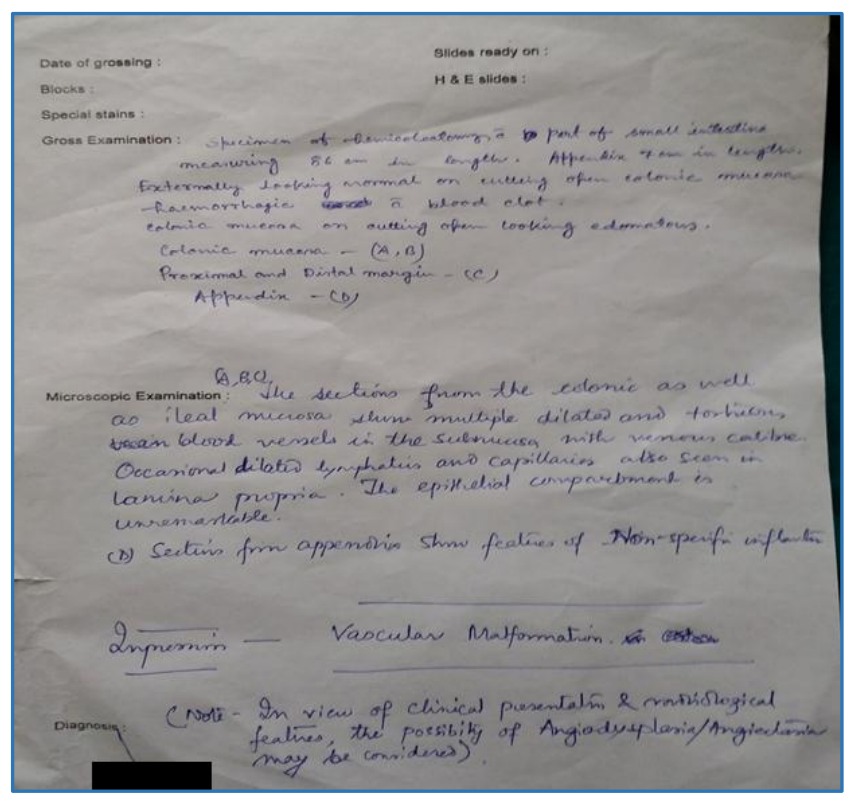

Histopathological Report-Dilated \& Tortuous Submucosal Blood Vessels in Colon and Ileum Suggestive of Vascular Malformations with Possibility of Angiodysplasia/Angioectasia

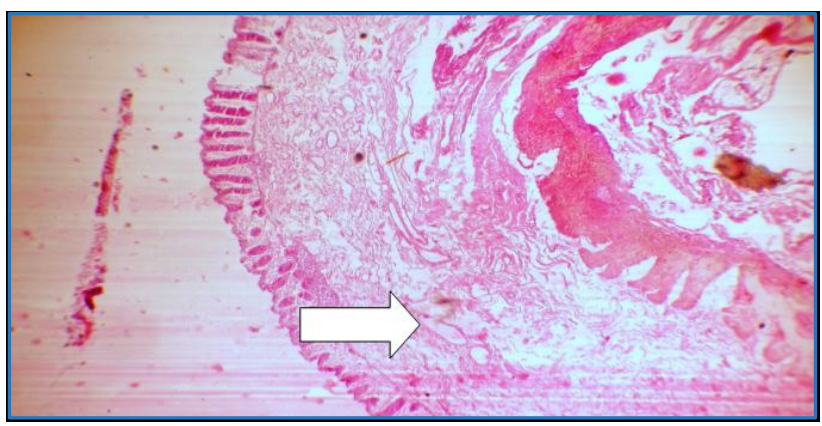




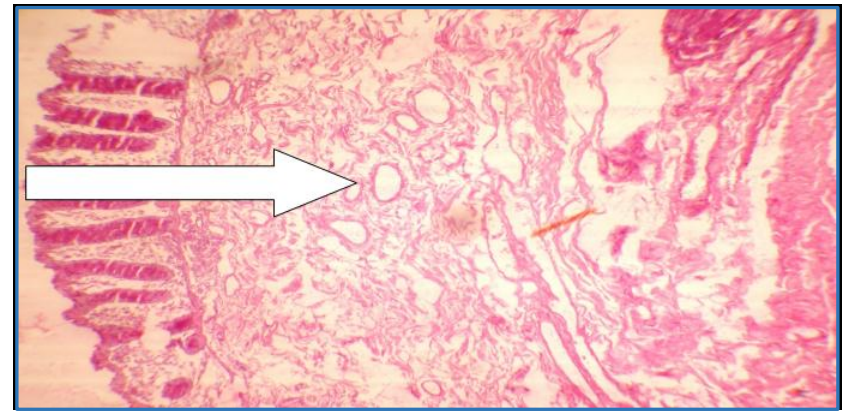

Histological slide showing dilated blood vessels in submucosa indicated by arrows

\section{DISCUSSION}

Angiodysplasia of the gastrointestinal tract are the most frequent cause of recurrent lower intestinal bleeding after age 60 years. $^{1}$

The lesions of angiodysplasia are generally small, $2-5 \mathrm{~mm}$ in diameter, single or multiple and consists of dilated mucosal capillaries draining into a tortuous submucosal vein. They arise from age related degeneration of previously normal colonic blood vessels.

The pathogenesis of the lesion seemed to be a congenital process in patients younger than 20 years of age. The number of cases increases with every year in people older than 20 years of age suggesting a degenerative process, then angiodysplasia is presumably an acquired lesion. ${ }^{3,4}$ Supporting this point, the mean age of patients with the finding in either the upper or lower intestinal tract is greater than 60 years old in most series.

So, it is a rare cause of lower gastrointestinal bleeding in young adults.
A literature search was made using Medline (National Library of Medicine, Bethesda, MD) to identify articles describing gastrointestinal vascular abnormalities as a case of massive lower gastrointestinal haemorrhage in young adults; only two of angiodysplasia. Greason KL et al ${ }^{5}$ identified vascular ectasia in descending colon in 21-year-old male patient with massive lower gastrointestinal haemorrhage and segmental colonic resection was performed. Parikh et $\mathrm{al}^{2}$ also performed a case of massive right-sided colonic angiodysplasia in a 22-year-old female.

\section{CONCLUSION}

Angiodysplasia is an uncommon cause of lower gastrointestinal haemorrhage in a young adult and some of them may need a more aggressive approach as in this case.

\section{REFERENCES}

1. Boley SJ, Sammartano R, Adams A, et al. On the nature and etiology of vascular ectasias of the colon. Degenerative lesions of aging. Gastroenterology 1977;72(4 Pt 1):650-60.

2. Parikh J, Kadam T, Desai I. Right-sided colonic angiodysplasia in a young patient-a case report. Indian J Pathol Microbial 2006;49(1):34-5.

3. Clouse RE, Costigan DJ, Mills BA, et al. Angiodysplasia as a cause of upper gastrointestinal bleeding. Arch Intern Med 1985;145(3):458-61.

4. Foutch PG. Angiodysplasia of the gastrointestinal tract. AM J Gastroenterol 1993;88(6):807-18.

5. Greason KL, Acosta JA, Magrino TJ, et al. Angiodysplasia as the cause of massive lower gastrointestinal hemorrhage in a young adult. Report of a case. Dis Colon Rectum 1996;39(6):702-4. 